\title{
Recurrent Pneumonia Revealing a Primary Lung Lymphoma Type
} BALT

\author{
H. El Maâroufi", S. Jennane, M. Mahtat, M. Ababou, A. Hammani, S. Ahchouch, M. Mikdame, K. Doghmi
}

Service d'Hématologie Clinique, Hôpital Militaire d'Instruction Mohammed V, Université Mohamed V-Souissi, Rabat, Marocco

DOI: $\underline{10.36347 / \text { sjmcr.2020.v08i01.028 }}$

| Received: 16.12.2019 | Accepted: 26.12.2019| Published: 29.01.2020

*Corresponding author: Hicham El Maaroufi

\section{Abstract}

Primary pulmonary lymphomas of MALT type (BALT) are rare and their therapeutic management is very heterogeneous but reflects the data of the literature. We report the case of a patient who presented for several months recurrent pneumonia and rebellious to antibiotics. A scano-guided biopsy with anatomo-pathological study allowed making the diagnosis. An immuno-chemotherapy with monoclonal antibodies and single-agent chemotherapy has achieved a good response.

Keywords: Primary pulmonary lymphomas, antibiotics, chemotherapy.

Copyright @ 2020: This is an open-access article distributed under the terms of the Creative Commons Attribution license which permits unrestricted use, distribution, and reproduction in any medium for non-commercial use (NonCommercial, or CC-BY-NC) provided the original author and source are credited

\section{INTRODUCTION}

Non-Hodgkin's lymphoma of the pulmonary malt or bronchial-associated lymphoid tissue (BALT) type is a rare hematological malignancy and accounts for only one percent of all non-Hodgkin lymphoma.

We report the case of a patient who presented for several months recurrent pneumonia and rebellious to antibiotics.

A scano-guided biopsy with anatomopathological study allowed making the diagnosis. An immuno-chemotherapy with monoclonal antibodies and single-agent chemotherapy has achieved a good response.

\section{Clinical Case}

This is a 68 -year-old chronic smoking patient with 30 packets / year weaned two years ago. The history of the disease dates back to six months by the installation of a pneumopathy with cough fat, purulent sputum all evolving in a context of fever. The evolution was marked by clinical improvement. Two months later, the patient is admitted to the emergency room for respiratory discomfort requiring hospitalization.

Standard radiography showed a left basal focus. Thoracic CT showed a left medio-basal alveolar focal airflow with air bronchogram measuring $28 \times 22$ mm (Fig-1).

A Scan-guided biopsy with pathology study poses the diagnosis of malt lymphoma. Immunohistochemistry shows positivity of CD20 and negativity of CD 23 and CD5. The tumor proliferation index (Ki67) is low at $15 \%$.

Pet scan and Chest-abdominal scan confirms the primitive nature of lymphoma (Fig-2).

The therapeutic management consisted of a treatment by Immunotherapy with anti-CD20 monoclonal antibodies (Rituximab). Four infusions were delivered with a good response. Maintenance treatment is underway to improve progression-free survival. 
H. El Maâroufi et al., Sch J Med Case Rep, Jan., 2020; 8(1): 91-95

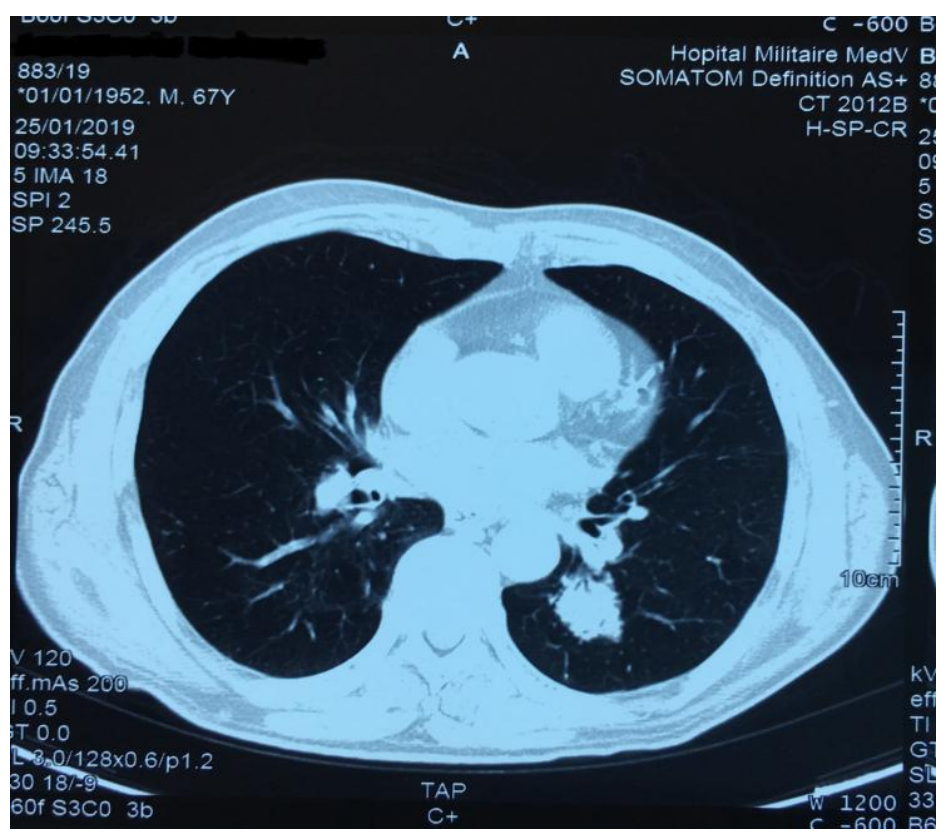

Fig-1: Chest CT showed a left medio-basal alveolar focal airflow with air bronchogram

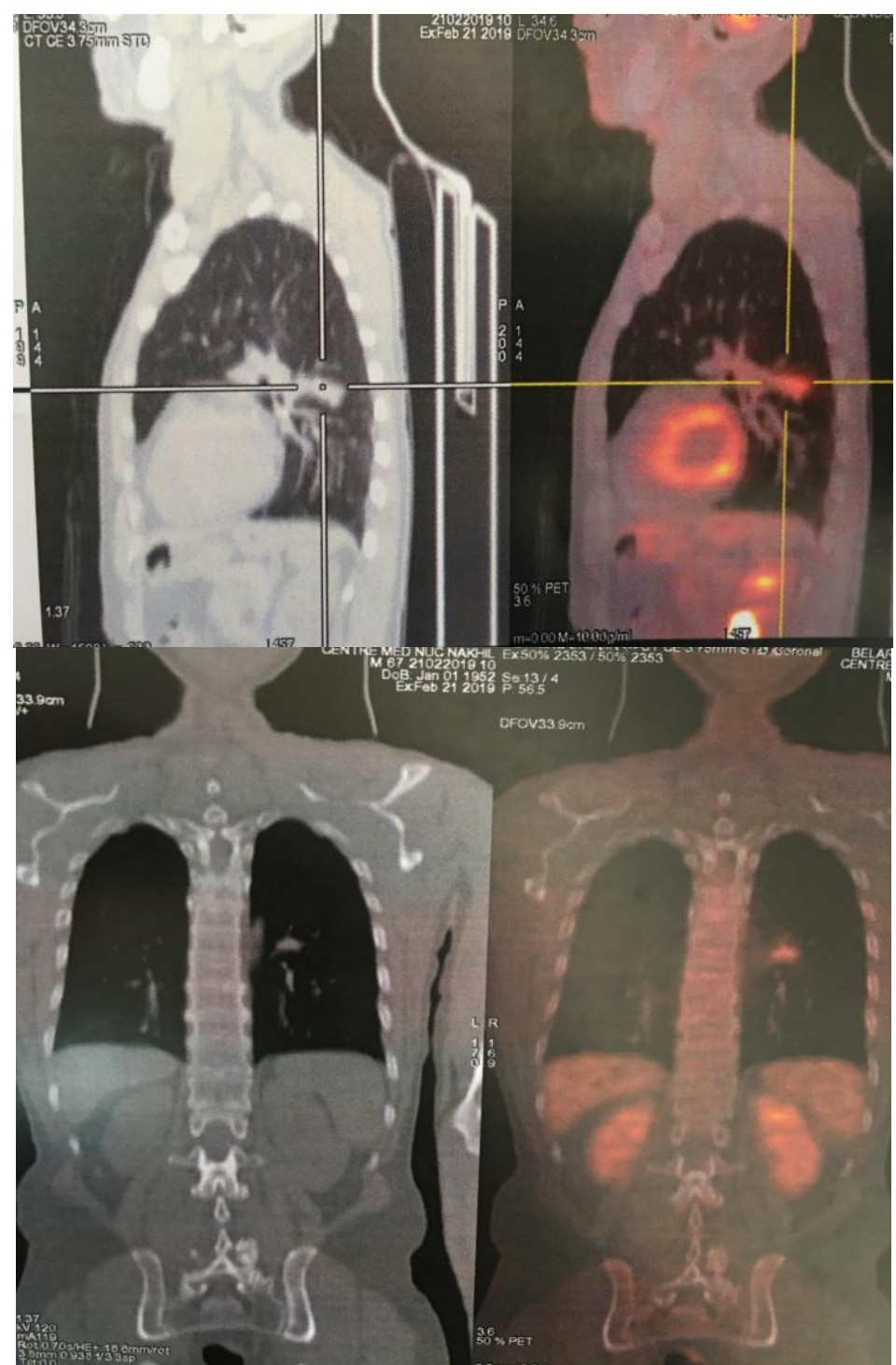

Fig-2: FDG-Pet-Scan showed a hypermetabolic pulmonary parenchymal condensation (Suv max: 4) 


\section{DISCUSSION}

Primary pulmonary lymphomas are rare, accounting for 0.5 to $1 \%$ of pulmonary neoplasms. MALT lymphomas are the most common primary pulmonary lymphoma [1,2]. The age of onset is around 50 to 60 years [3]. The prevalence of smoking is not higher than that of the general population. Women are as affected as men. In a recent series, $16 \%$ of patients had autoimmune disease [3].

In half of the cases, the patients are asymptomatic and the investigations are then started on the presence of a radiological pulmonary abnormality of fortuitous discovery. When present, the symptoms are nonspecific. General signs [fever or weight loss] are observed in less than one in four patients, and should suggest a transformation into high-grade lymphoma [4].

The usual radiological aspect is that of an alveolar opacity, localized, in the form of nodule or mass, with an air bronchogram [5]. Computed tomography is more sensitive than standard radiography and shows bilateral lesions (60 to $70 \%$ ) and multifocal lesions (70 to $77 \%$ ) and the almost constant presence of light corresponding to bronchial lumen. The presence of bronchiectasis by traction within the lesions is suggestive of the diagnosis [5]. Hilar or mediastinal lymphadenopathies may be present [5, 6]. FDG-PET (18-fluorodeoxyglucose positron emission tomography) shows moderate hyperfixation in $80 \%$ of cases $[3,7]$.

Bronchial fibroscopy is usually macroscopically normal [8]. Abnormalities ranging from inflammatory mucosa to bronchial stenosis can be observed [6]. Bronchial biopsies are all the more costeffective than those achieved with endobronchial lesions [8]. Transbronchial biopsies or CT biopsy puncture are cost-effective for the diagnosis of more peripheral lesions. It is only in the absence of specific lesion on these samples that a surgical gesture for diagnostic purposes will be considered.

Bronchioloalveolar lavage has a diagnostic orientation value if there is lymphocyte alveolitis but contributes to the differential diagnosis of chronic alveolar opacity [9].

The diagnosis of MALT type LPP is histological and is based on the analysis of bronchial biopsies, transthoracic transbronchial or surgical specimens [10].

The macroscopic appearance is that of a whitish mass, soft and poorly limited. The microscopic aspect typically finds a proliferation made of lymphoid cells of small to medium size, centrocyte-like type and or monocytoid or plasmocytic cells [10].
Immunohistochemical analysis is required and the minimum required panel must be labeled with CD20, CD10, CD5, cyclin D1 [10].

Molecular biology techniques help to determine clonality by demonstrating a rearrangement of immunoglobulin heavy or light chain genes. These techniques also highlight the different translocations.

Ganglion lymphoma with secondary pulmonary dissemination will be eliminated by thoracic-abdominopelvic CT with injection of contrast medium. Osteo-medullary biopsy shows signs of invasion in $13 \%$ to $30 \%$ of patients $[3,11]$. The involvement of other lymphoid mucosal sites is present in $25-35 \%$ of cases and is more frequent for MALT lymphomas unrelated to the digestive tract $[11,12]$. The assessment of other mucosal lymphoid sites may include an ophthalmological and ENT examination (MRI or ultrasound of the salivary and lacrimal glands if doubtful), oesogastroduodenal fibroscopy, and colonoscopy (and small intestine transit for some).

FDG-PET is not routinely recommended because it is poorly evaluated [10]. Some sites like the stomach or bone marrow are associated with an excess of false negatives.

MALT lymphomas have a favorable evolution with a survival greater than 5 years in more than $80 \%$ of cases and a median survival of more than 10 years $[3,6$, 11]. Overall survival was shown to be longer than lymphoma in the nodal and splenic marginal zone [11]. The survival of patients with MALT lymphoma has not been shown to be different from that of the general population [1, 13]. The median survival of MALT lymphoma of the digestive tract does not differ from that of the other sites, but the progression-free survival would be shorter for extradigestive and particularly pulmonary localizations [14].

Prognostic factors of MALT lymphomas are not clearly demonstrated. For lung disease, a retrospective study of 48 patients not highlighted any prognostic factor, whether the presentation, bilaterality postoperative classification, cancer surgery, adjuvant chemotherapy or different histological criteria [15].

In contrast, the t $(11 ; 18)$ has been mainly observed in MALT lymphomas and not in processed forms [16]. The presence of this translocation could however intensify justify the treatment [17].

Therapeutic recommendations for MALT lymphomas have recently been published but are focused on the most common digestive damage [10].

The lack of emphasis in the lung of a microbial antigen associated or causal as Helicobacter pylori in the stomach deprives us of antibiotic treatment. 
The treatments used are surgery, chemotherapy and radiation therapy [3]. The relative effectiveness of these treatments cannot be analyzed in the absence of comparative series, and no treatment is debatable [18].

Surgical resection or radiation therapy can be practiced in case of localized injury $[6,19]$. The use of chemotherapy alone is accepted in case of bilateral disease or extrapulmonary, relapse or progression; the CHOP combination chemotherapy showed no therapeutic superiority $v s$ a monochemotherapy by chlorambucil or fludarabine $[3,6]$. The monoclonal anti-CD20 (rituximab) is effective and a response rate of $70 \%$ all sites [19] but with a high relapse rate (36\%).

A prospective phase III study in 231 patients was performed to evaluate the effect of adding rituximab to chlorambucil [20]. The main objective was to show an improvement of the event-free survival rate at 5 years, was achieved in the dual therapy group $(68 \%$ vs $50 \%$ ). Dual therapy increased the rate of complete remission compared to chlorambucil alone (78 vs 65\%) but did not change the 5-year survival rate by $89 \%$. Dual therapy increased the progression-free survival rate at 5 years, but the difference was not significant [20]. The addition of rituximab to chlorambucil may be beneficial for patients with $\mathrm{t}(11: 18)$, a retrospective study reported an increase in remission rate of $45 \%$ to $100 \%$ at 6 weeks for patients treated with dual therapy compared with to patients treated with rituximab alone [17]. A phase III study is currently underway to specifically evaluate the benefit of rituximab alone compared with dual therapy and chlorambucil alone.

A consolidation study by an anti-CD20 other than rituximab is ongoing. Drugs targeting the NF-B pathway such as bortezomib are also being evaluated.

A local treatment will be offered as soon as it is feasible. Depending on the age, symptoms, extent of disease and condition, simple monitoring can also be proposed.

\section{CONCLUSION}

Primary pulmonary lymphomas of MALT type (BALT) are rare and their therapeutic management is very heterogeneous but reflects the data of the literature.

Recurrent pneumonia and rebellious was the circumstance of discovery. A multi-disciplinary care is needed to treat this type of lymphoma. An immunochemotherapy yielded a good response.

\section{REFERENCES}

1. Kurtin PJ, Myers JL, Adlakha H, Strickler JG, Lohse C, Pankratz VS, Inwards DJ. Pathologic and clinical features of primary pulmonary extranodal marginal zone B-cell lymphoma of MALT type.
The American journal of surgical pathology. 2001 Aug 1;25(8):997-1008.

2. Li G, Hansmann ML, Zwingers T, Lennert K. Primary lymphomas of the lung: morphological, immunohistochemical and clinical features. Histopathology. 1990 Jun;16(6):519-31.

3. Borie R, Wislez M, Thabut G, Antoine M, Rabbat A, Couderc LJ, Monnet I, Nunes H, Blanc FX, Mal H, Bergeron A. Clinical characteristics and prognostic factors of pulmonary MALT lymphoma. European Respiratory Journal. 2009 Dec 1;34(6):1408-16.

4. Cadranel J, Wislez M, Antoine M. Primary pulmonary lymphoma. European Respiratory Journal. 2002 Sep 1;20(3):750-62.

5. Wislez M, Cadranel J, Antoine M, Milleron B, Bazot M, Mayaud C, Carette MF. Lymphoma of pulmonary mucosa-associated lymphoid tissue: CT scan findings and pathological correlations. European Respiratory Journal. 1999 Aug 1;14(2):423-9.

6. Cordier JF, Chailleux E, Lauque D, ReynaudGaubert M, Dietemann-Molard A, Dalphin JC, Blanc-Jouvan F, Loire R. Primary pulmonary lymphomas: a clinical study of 70 cases in nonimmunocompromised patients. Chest. 1993 Jan 1;103(1):201-8.

7. Zhang WD, Guan YB, Li CX, Huang XB, Zhang FJ. Pulmonary mucosa-associated lymphoid tissue lymphoma: computed tomography and $18 \mathrm{~F}$ fluorodeoxyglucose-positron emission tomography/computed tomography imaging findings and follow-up. Journal of computer assisted tomography. 2011 Sep 1;35(5):608-13.

8. Cordier JF, Chailleux E, Lauque D, ReynaudGaubert M, Dietemann-Molard A, Dalphin JC, Blanc-Jouvan F, Loire R. Primary pulmonary lymphomas: a clinical study of 70 cases in nonimmunocompromised patients. Chest. 1993 Jan 1;103(1):201-8.

9. Drent M, Wagenaar SS, Mulder PH, Van VelzenBlad H, Diamant M, Van den Bosch JM. Bronchoalveolar lavage fluid profiles in sarcoidosis, tuberculosis, and non-Hodgkin's and Hodgkin's disease: an evaluation of differences. Chest. 1994 Feb 1;105(2):514-9.

10. Dreyling M, Thieblemont C, Gallamini A, Arcaini L, Campo E, Hermine O, Kluin-Nelemans JC, Ladetto M, Le Gouill S, Iannitto E, Pileri S. ESMO Consensus conferences: guidelines on malignant lymphoma. part 2: marginal zone lymphoma, mantle cell lymphoma, peripheral $\mathrm{T}$ cell lymphoma. Annals of Oncology. 2013 Feb 20;24(4):857-77.

11. Thieblemont C, Berger F, Dumontet C, Moullet I, Bouafia F, Felman P, Salles G, Coiffier B. Mucosa-associated lymphoid tissue lymphoma is a disseminated disease in one third of 158 patients analyzed. Blood. 2000 Feb 1;95(3):802-6. 
12. Raderer M, Vorbeck F, Formanek M, Österreicher C, Valencak J, Penz M, Kornek G, Hamilton G, Dragosics B, Chott A. Importance of extensive staging in patients with mucosa-associated lymphoid tissue (MALT)-type lymphoma. British journal of cancer. $2000 \mathrm{Aug} ; 83(4)$ :454-457.

13. Koss MN, Hochholzer L, Nichols PW, Wehunt WD, Lazarus AA. Primary non-Hodgkin's lymphoma and pseudolymphoma of lung: a study of 161 patients. Human pathology. 1983 Dec 1;14(12):1024-38.

14. Ueda K, Terui Y, Yokoyama M, Sakajiri S, Nishimura N, Tsuyama N, Takeuchi K, Hatake K. Non-gastric advanced mucosa-associated lymphoid tissue (MALT) lymphoma has worse prognosis than gastric MALT lymphoma even when treated with rituximab-containing chemotherapy. Leukemia \& lymphoma. 2013 Sep 1;54(9):1928-33.

15. Ferraro P, Trastek VF, Adlakha H, Deschamps C, Allen MS, Pairolero PC. Primary non-Hodgkin's lymphoma of the lung. The Annals of thoracic surgery. 2000 Apr 1;69(4):993-7.

16. Farinha P, Gascoyne RD. Molecular pathogenesis of mucosa-associated lymphoid tissue lymphoma. Journal of Clinical Oncology. 2005 Sep 10;23(26):6370-8.
17. Lévy M, Copie-Bergman C, Amiot A, Dupuis J, Baleur YL, Belhadj K, Hémery F, Sobhani I, Delfau-Larue MH, Leroy K, Haioun C. Rituximab and chlorambucil versus rituximab alone in gastric mucosa-associated lymphoid tissue lymphoma according to $\mathrm{t}(11 ; 18)$ status: a monocentric nonrandomized observational study. Leukemia \& lymphoma. 2013 May 1;54(5):940-4.

18. Addis BJ, Hyjek E, Isaacson PG. Primary pulmonary lymphoma: a re-appraisal of its histogenesis and its relationship to pseudolymphoma and lymphoid interstitial pneumonia. Histopathology. $1988 \mathrm{Jul} ; 13(1): 1-17$.

19. Conconi A, Martinelli G, Thiéblemont C, Ferreri AJ, Devizzi L, Peccatori F, Ponzoni M, Pedrinis E, Dell'Oro S, Pruneri G, Filipazzi V. Clinical activity of rituximab in extranodal marginal zone B-cell lymphoma of MALT type. Blood. 2003 Oct 15;102(8):2741-5.

20. Zucca E, Conconi A, Laszlo D, López-Guillermo A, Bouabdallah R, Coiffier B, Sebban C, Jardin F, Vitolo U, Morschhauser F, Pileri SA. Addition of rituximab to chlorambucil produces superior event-free survival in the treatment of patients with extranodal marginal-zone B-cell lymphoma: 5-year analysis of the IELSG-19 Randomized Study. Journal of Clinical Oncology. 2013 Jan 7;31(5):565-72. 